\title{
The influence of social support on health and wellbeing among women with and without children
}

\author{
Melissa Graham \\ La Trobe University
}

\begin{abstract}
Social support is a significant determinant of health and well-being, with poorer social support leading to poorer health outcomes. Despite this, little is known about the impact of social support on health and wellbeing among women without children, or how this compares to women with children. Drawing on data from 683 women, who participated in both Wave 1 (1997) and Wave 4 (2006) of the Negotiating the Life Course study, and were aged 28 to 66 years (at Wave 4), regression models were used to examine the relationship between health and wellbeing and social support by motherhood status (mother or childless). Dissatisfaction with the number of close friends was associated with poorer general health ( $r h o=-0.23, p<0.001$ ). Women without children reported poorer general health than mothers even after controlling for potentially confounding variables $(\operatorname{Exp}(B)=1.11,95 \% \mathrm{Cl} 1.01-1.22)$. Not mothering has implications for women's health. Further investigation of the type, role and quality of social support within kin and non-kin relationships is required to better understand the role of social support on health, and if this differs between women with and without children.
\end{abstract}

Keywords: social support, health and wellbeing, motherhood, childlessness

\section{Introduction}

The reproductive choices a woman makes in her life, and indeed those outside of her own control, can have consequences for both her social connectedness and her health and wellbeing across the life course. While it has been well established that poor social connectedness and support is associated with poor health outcomes and increased risk of premature mortality from almost all causes (see for example, Berkman \& Glass, 2000; Commission on Social Determinants of Health (CSDH), 2008; Eng, Rimm, Fitzmaurice \& Kawachi, 2002), little is known about the role of social support and how it affects the health and wellbeing of women who do not mother in Australia, particularly in relation to how this compares to mothers. Understanding any potential consequences for women who do not mother is of particular significance given the growing numbers of women in Australia (Australian Bureau of Statistics (ABS), 2008; 2012) and other nations (Miettinen, Rotkirch, Szalma, Donno \& Tanturri, 2015) who do not have children.

Women who do not mother are a group which can often bare a degree of covert social distain and even overt social distance (Gillespie, 2000; Park, 2002; Turnbull, Graham \& Taket, 2016b; Veevers, 1974), which has consequences for a woman's social support network.

Corresponding author: Melissa Graham (M.Graham3@latrobe.edu.au) 
Research demonstrates that compared to married parents, married childless couples have weaker social supports across the life-course (Ishii-Kuntz \& Seccombe, 1989); the childless are more likely to have limited social network supports (Wenger, Dykstra, Melkas \& Knipscheer, 2007); and the older childless (those aged 85 years or more) have social networks with less support potential (Vikström et al., 2011) than parents. Furthermore, the childless have statistically significantly smaller social networks than parents (biological and blended families) both in midlife (25-46 years) and older age (60-86 years) (Lang, Wagner, Wrzus \& Neyer, 2013). In particular, women without children have fewer social networks and less support than women with children (Albertini \& Mencarini, 2011; Dykstra, 2006; Ishii-Kuntz \& Seccombe, 1989).

In contrast, Wenger and colleagues (2007) suggest that while women without children have less contact with relatives, they were more likely to see friends frequently and have higher levels of neighbourhood contacts than mothers. Furthermore, older women without children who are in good health have been found to be more likely to report contact with friends and family than women with children (Bachrach, 1980). A German study with 124 heterosexual couples found there was a social segregation between women with and without children and the social networks of voluntarily and involuntarily childless couples differed by structure, perceived closeness and reciprocity of support (Wagner, Wrzus, Neyer \& Lang, 2015a).

While previous research has demonstrated there are negative health and wellbeing consequences associated with not mothering (see for example, Agerbo, Mortensen \& MunkOlsen, 2013; Chou \& Chi, 2004; Graham, 2015; Graham, Hill, Shelley \& Taket, 2011; Hansen, Slagsvold \& Moum, 2009; Holton, Fisher \& Rowe, 2010; Kendig, Dykstra, Van Gaalen \& Melkas, 2007; Koropeckyj-Cox, 1998; Lawlor et al., 2003; McMunn Bartley, \& Kuh, 2006; Nomaguchi \& Milkie, 2003; Wu \& Hart, 2002), there has been a paucity of research regarding the role of social support, and in particular satisfaction with friendship relationships, on health and if this differs between women with and without children. The number of close friends one has in their social network, and their satisfaction with this, forms one aspect of social support. An important aspect of social support is an individual's ability to be involved in reciprocal exchange. If an individual is considered deficient in a particular area they are perceived to have no means by which they may 'give back'. Subsequently, individuals can become excluded from social relations (Reidpath, Chann, Gifford \& Allotey, 2005). In the case of women without children, these women may be considered to have little social value, due to dominant pronatalist ideologies, and as a result may experience dissatisfaction with their friendships (Graham, McKenzie, Turnbull \& Taket, 2019; Turnbull et al., 2016b).

It has been posited that older childless people are as adept as parents in being able to sustain their style of life unless faced with poor health. Confronted with poor health, the childless become vulnerable and socially isolated (Bachrach, 1980), as they typically have fewer and weaker social supports and network members, with a strong commitment to and expectation in the provision of care, despite any reciprocity (Dykstra, \& Hagestad, 2007; Wenger et al., 2007). However, a Swedish study of older people (aged 85 years or more) found no psychological health (including loneliness, depression, happiness and life satisfaction) differences between those with and without children (Vikström et al., 2011), despite those without children having weaker social supports.

Albertini and Mencarini (2014, p. 333) posit that "family networks are at the core of the individual's social embeddedness: not only do they usually provide the largest amount of support an individual needs all through her / his life, they also bridge the individual and society". Their research found people without children aged 49 years or less received fewer social supports from outside their own household than those with children, and older people without children received less tangible supports but more emotional support than people with children, and these differences increased with age. These findings are suggestive of poor 
social support for women who do not mother, not only during the transitional years but also in the later years when tangible supports become increasingly important, particularly as the health deteriorates (Albertini \& Mencarini, 2014). Furthermore, this has the potential to perpetuate any existing health and wellbeing differentials between women with and without children.

Taken together, previous research is inconclusive but is suggestive of poorer health and wellbeing, and social supports for women who do not mother. The aim of this study was to examine the relationship between health and wellbeing and social support by motherhood status (mother or childless).

\section{Methods}

The Negotiating the Life Course (NLC) Study is a longitudinal study designed to examine changing life courses and decision-making among Australians. The NLC Study was undertaken by the Australian Demographic and Social Research Institute, Australian National University and the School of Social Science, University of Queensland between 1997 and 2009, with five waves of data collected (1997, 2000, 2003, 2006 and 2009); however only the first four waves of data were available for analysis at the time of the current study (Australian Demographic \& Social Research Institute, 2009; Breusch \& Gray, 2005; Reimondos \& Trevenar, 2013). The methods used in the NLC study have been reported elsewhere in detail (see for example, Baxter, Hewitt \& Haynes, 2008; McDonald, Evans, Baxter \& Gray, 2000). Briefly, the electronic white pages was used as a sampling frame to randomly select household's nationwide. Within each household, participants were randomly selected from all eligible adults in the household based on the person aged 18 to 54 years with the most recent birthday. The final sample at Wave 1 consisted of 2,231 participants between the ages of 18 and 54 years (response rate 52-63\%). Data were collected using computer-assisted telephone interviewing after verbal informed consent was obtained (McDonald et al., 2000). The current analysis includes women aged 18 years or more who participated in both Waves 1 and 4 of the NCL study. A total of 683 women (54.8\%) were retained from Waves 1 to 4.

NLC data were provided in de-identified unit record format. Applications to access data from the NLC study can be submitted via the Australian Data Archive (http://ada.edu.au/). An application was submitted and approved by the Australian Social Science Data Archive and the owners of the data (the Australian Demographic and Social Research Institute, Australian National University and the School of Social Science, University of Queensland) to access the data. An application for ethics exemption was approved by the Deakin University Human Research Ethics Committee (DUHREC 2012-342). Deakin University requires all research to undergo an ethical review process. The de-identified nature of data used for the current analysis meant ethical approval was sought and obtained in the form of an exemption.

\section{Measures}

The main variables of interest in this study were divided into three areas: demographic characteristics; social support; and health and wellbeing. Demographic characteristics included age, partner status, highest level of educational attainment, employment status and motherhood status. Partnered status was measured using a four-category response option (not in a relationship, in a relationship but not living together, living in a relationship but not legally married, and married and living with spouse). Partner status was used rather than marital status to account for the respondent's current relationship status. Highest level of educational attainment was computed based on two items: what was the highest level of schooling completed and attainment of a post-school qualification. Employment status was computed based on two items: last week, did you have a paid job of any kind and did you actively look for work at any time in the past four weeks. Motherhood status (mother or 
childless) was computed based on the total number of children ever given birth to, respondent partners' biological children, children living with respondent, and fostered or adopted children.

Social support is known to interact with health via several pathways, however regardless of the pathway, social support is a predictor of health outcomes and is an important aspect to understand in relation to this stigmatised population group. "Support is generally considered as an exchange or transaction between people" (Berkman, 1984, p. 415). Social support was measured on a nine-point scale $(1=$ extremely dissatisfied, $5=$ mixed feelings and $9=$ extremely satisfied) using a single variable: satisfaction with 'the number of close friends you have'. This item provides an indication of the level of satisfaction with the closeness of contacts within friendship networks from which they may receive emotional, instrumental, informational, or appraisal support (Berkman \& Glass, 2000).

The General Health Questionnaire (12 item) which has been previously validated (see for example, Goldberg et al., 1997) was used to assess health and wellbeing. The 12 items were measured using a four-point scale from 'better than usual' to 'much less than usual', 'not at all' to 'much more than usual', or 'more so than usual' to 'much less than usual'. The 12 items were combined to produce a summary score ranging from zero to 36 with lower scores indicating better general health. Self-rated health was measured using the standard single item 'how would you rate your health in general, is it excellent, good, fair or poor' (Bowling, 2005).

\section{Analysis}

Women ( $n=683$ ) who participated in Waves 1 and 4 of the NLC Study were included in the current analysis. All analysis was conducted with women respondents who were aged 18 years or more at Wave 4. Descriptive statistics were conducted for all of the variables of interest. Comparison between women with and without children and partner status, education and employment were made using chi square tests. The t-test for independent samples was used to test for differences between women with and without children on age, general health scores and satisfaction with number of close friends. The relationship between general health and satisfaction with number of close friends was assessed using Spearman's correlation. Generalised linear regression models were constructed to determine the effect of social support on health by motherhood status and controlling for demographic characteristics and self-rated health at Wave 1 . Statistically significantly demographic characteristics were retained in the model as potential confounding variables (Table 1). Self-rated health at Wave 1 was used to control for health status at Wave 4 as the General Health Questionnaire was not administered at Wave 1. Analysis of Wave 4 self-rated health and the General Health Questionnaire score suggests a moderate correlation (rho $=-0.40 ; p<0.001$ ) with those reporting better general health also reporting better self-rated health.

\section{Results}

Most $(n=597 ; 87.4 \%)$ of the women were mothers. The mean age of the women was 48.5 years $(S D=8.71)$. Mothers $(m=49.08, S D=8.37)$ were older than non-mothers $(m=44.53$, $\mathrm{SD}=9.92$; mean difference $=4.55, \mathrm{t}=4.05, \mathrm{p}<0.001$ ). Most women were married and living with their spouse $\left(66.4 \%, X^{2}=39.77, \mathrm{df}=3, p<0.001\right)$. Motherhood status was associated with highest level of educational attainment $\left(x^{2}=25.40, \mathrm{df}=4, \mathrm{p}<0.001\right)$ and employment $\left(x^{2}=5.95, d f=2, p=0.05\right)$. Table 1 describes the characteristics of the sample. 
Table 1: Demographic characteristics of the women by motherhood status

\begin{tabular}{|c|c|c|c|c|c|c|}
\hline \multirow{2}{*}{ (2) } & \multicolumn{2}{|l|}{ Childless } & \multicolumn{2}{|l|}{ Mother } & \multirow[b]{2}{*}{$x^{2}$} & \multirow[b]{2}{*}{$\mathrm{p}$} \\
\hline & $\mathrm{n}$ & $\%$ & & $\%$ & & \\
\hline Partner Status $(n=682)$ & & & & & 39.77 & $<0.001$ \\
\hline Not in a relationship & 29 & 34.1 & 99 & 16.6 & & \\
\hline In a relationship, not living together & 9 & 10.6 & 23 & 3.9 & & \\
\hline Living in a relationship but not legally married & 16 & 18.8 & 53 & 8.9 & & \\
\hline Married and living with spouse & 31 & 36.5 & 422 & 70.7 & & \\
\hline Highest level of educational attainment $(n=683)$ & & & & & 25.40 & $<0.001$ \\
\hline Incomplete secondary school (or less) & 7 & 8.1 & 146 & 24.5 & & \\
\hline Completed secondary school & 28 & 32.6 & 120 & 20.1 & & \\
\hline Post-secondary & 19 & 22.1 & 200 & 33.5 & & \\
\hline University undergraduate degree & 20 & 23.3 & 73 & 12.2 & & \\
\hline University post graduate & 12 & 14.0 & 58 & 9.7 & & \\
\hline Employment $(n=683)$ & & & & & 5.95 & 0.05 \\
\hline Employed & 67 & 77.9 & 440 & 73.7 & & \\
\hline Not employed and looking for work & 5 & 5.8 & 13 & 2.2 & & \\
\hline Not employed and not looking for work & 14 & 16.3 & 144 & 24.1 & & \\
\hline
\end{tabular}


General health scores were associated with satisfaction with the number of close friends (rho $=-0.23, p<0.001$ ) indicating that poorer general health was associated with less satisfaction with the number of close friends. The mean general health score for all women was 10.72 (SD $=4.92)$ with childless women reporting poorer general health scores $(\mathrm{m}=11.94, \mathrm{SD}=6.37)$ than mothers $(m=10.45, S D=4.66 ; t=-2.47 ; p=0.05)$. The mean satisfaction with the number of close friends was $7.28(S D=1.84)$ with mothers reporting lower levels of satisfaction $(m=7.25$; $S D=1.83)$ than childless women $(m=7.53$; $S D=1.90)$; however this was not statistically different $(t=-1.35 ; p=0.18)$.

Childless women reported poorer general health than mothers $(\operatorname{Exp}(B)=1.13,95 \% \mathrm{Cl} 1.03-$ 1.24) and this effect remained after controlling for satisfaction with the number of close friends, prior self-reported health, age, partner status, employment status and highest level of educational achievement $(\operatorname{Exp}(B)=1.11,95 \% \mathrm{Cl} 1.01-1.22)$. Table 2 presents general health by motherhood status and social support controlling for self-reported health at Wave 1 and demographic characteristics.

Table 2: Generalised linear regression of general health by motherhood status adjusted for satisfaction with the number of close friends, self-rated health and demographic characteristics $(n=679)$

\begin{tabular}{lll}
\hline & Exp(B) & $95 \% \mathrm{Cl}$ \\
\hline $\begin{array}{l}\text { Motherhood status } \\
\text { Childless }\end{array}$ & 1.11 & $1.01-1.22$ \\
\hline Satisfaction with number of close friends & 0.95 & $0.93-0.96$ \\
\hline Self-rated health (Wave 1) & & \\
$\quad$ Excellent & 0.78 & $0.65-0.93$ \\
Good & 0.85 & $0.71-1.02$ \\
Fair & 0.94 & $0.77-1.15$ \\
Poor & - & - \\
\hline Age & 0.999 & $0.996-1.00$ \\
\hline Partner Status & & \\
Not in a relationship & 1.17 & $1.08-1.27$ \\
In a relationship, not living together & 1.12 & $0.96-1.28$ \\
Living in a relationship but not legally married & 0.93 & $0.84-1.03$ \\
Married and living with spouse & - & - \\
\hline Employment & & \\
Employed & 0.95 & $0.88-1.02$ \\
Not employed and looking for work & 1.04 & $0.86-1.27$ \\
Not employed and not looking for work & - & - \\
\hline Highest level of educational attainment & & \\
Incomplete secondary school (or less) & & $0.87-1.10$ \\
Completed secondary school & 0.96 & $0.86-1.07$ \\
Post-secondary & 0.96 & $0.87-1.07$ \\
University undergraduate degree & 0.97 & $0.86-1.10$ \\
University post graduate & - & - \\
\hline
\end{tabular}

\section{Discussion}

The relationship between health and social support has been well established, and findings from this study similarly indicate poorer general health is associated with greater dissatisfaction with the number of close friends. While women without children reported greater levels of satisfaction with the number of close friends compared with mothers, the difference was not statistically significant. This finding is contrary to some previous research which suggests women without children have weaker social supports (Albertini \& Mencarini, 2011; Dykstra, 2006; Ishii-Kuntz \& Seccombe, 1989), having one or more children is an 
effective buffer against social isolation (Bachrach, 1980), and children provide social benefits such as broadening and activating social networks during the transitional years (Nomaguchi \& Milkie, 2003). It is possible the findings from the current study is a reflection of the measure used, as earlier research indicates women without children have more contact with friends than mothers (Bachrach, 1980; Wenger et al., 2007), while mothers are more likely to have stronger kin relationships (Wagner, Wrzus, Neyer \& Lang, 2015b). Furthermore, the current findings may reflect the small sample of women without children and the inability to distinguish between types of women without children. Previous research indicates women who are voluntarily childless report more reciprocal social relationships compared with the involuntarily childless (Wagner, et al., 2015b). The current study was only able to assess satisfaction with the number of close friends, which does not tell us about perceived or actual supports, quality of supports, or the role of kin relationships. Further investigation of the perceived, actual and quality of social supports is required, along with the kin relationships to better understand the role of social support on health in relation to motherhood status.

Whether or not a woman has children has implications for her health. In the current study, women without children reported poorer general health than mothers, and this effect remained after controlling for potential confounders. A possible explanation for this finding is that a woman's reason for her childlessness is her poor health, however, by controlling for selfreported health at Wave 1, to some extent the potential for reverse causation has been mitigated. Congruent with previous research, women without children's poorer health may be a result of unfulfilled motherhood desires and expectations, particularly for the infertile (Klemetti, Raitanen, Sihvo, Saarni \& Koponen, 2010) and the societal expectations of women to be mothers (Graham, 2015; Huijts, Kraaykamp \& Subramanian, 2013). It has been argued that women's social identity is attached to the role of wife and mother, and acceptable behaviours in those roles are based on social norms (Eckert, 1993). Gender relations are complex and may produce conflict across the life course (Connell, 2002), for example when women are unable to or choose not to have children this creates conflict as it violates the gender norms in pronatalist societies (Rich, Taket, Graham \& Shelley, 2011; Turnbull, Graham, \& Taket, 2016a; Turnbull et al., 2016b; Turnbull, Graham \& Taket, 2016c). This violation of gender norms results in the 'othering' of women without children and for those women who choose to be childless, being further labeled as deviant (Gillespie, 2000; Letherby, 1999), both of which can have negative consequences for health.

The current analysis could not determine women's reasons for not having children, however, it could be these very reasons that explain the poorer health of these women. Furthermore, women's future mothering intentions are unclear. Some women may be what have been described as postponers (Maher \& Saugeres, 2007; Rowland, 1982; Rowlands \& Lee, 2006; Tietjens-Meyers, 2001), while others may be voluntary (Cannold, 2004; 2005) or involuntarily childless (Daniluk, 2001; Letherby, 1999), or childless by circumstance (Cannold, 2005). Voluntary and involuntary childlessness are not either/or categories, rather they are opposing ends of a continuum which women may move along during different stages in their life (Letherby, 1999; 2000; 2002). As such, childlessness is not a fixed position, rather it is one that changes with time, age, context and life circumstances (Morell, 1994; Park, 2002). However, even after controlling for age and partner status, factors known to be associated childbearing, the effect remained.

The main limitation of this study was the high numbers of losses to follow up ( $n=1,246$ at Wave 1 and $n=683$ at Wave 4) reducing the number of women available for inclusion at Wave 4. This has implications for the statistical power of the study to examine differences between the two groups of women (those with and those without children) at Wave 4, thus reducing the capacity to control for any other potentially confounding variables. Analysis based on Wave 1 data suggests women who completed both Waves 1 and 4 were older at Wave 1 (mean age $=38.63$, SD $=8.77$ ) compared to women who were lost to follow-up by 
Wave 4 (mean age $=33.83, \mathrm{SD}=9.71$; mean difference $=-4.8, \mathrm{t}=-9.07, \mathrm{p}<0.001$ ). Women lost to follow-up and women who remained in the study differed in terms of partner status $\left(x^{2}\right.$ $=30.4, \mathrm{df}=3, \mathrm{p}<0.001)$, highest level of education completed $\left(x^{2}=14.59, \mathrm{df}=4, \mathrm{p}=0.006\right)$ and hours worked in the previous week (mean difference $=2.61, t=2.2, p=0.028$ ). Given this, caution must be taken in the interpretation and extrapolation of these findings to the wider population.

\section{Conclusion}

The findings from this study suggest health differences between women with and without children exist, and women without children report poorer general health and this effect remained after taking into account satisfaction with the number of close friends, prior selfreported health, age, partner status, employment status and highest level of educational attainment. No differences in satisfaction with the number of close friends was observed between women with and without children. These findings require further examination with a larger sample of women and a wider range of social support measures to better determine if there are differences in social support between women with and without children including the role and types of social support, and if these negate potential negative health outcomes for women. These findings have implications for women's health and wellbeing, particularly for women who do not mother, which need to be considered and addressed by health professionals.

\section{Acknowledgements}

I would like to acknowledge both the Negotiating the Life Course project and the Australian Social Science Data Archive for providing access to this data. Further I declare that those who carried out the original analysis and collection of the data bear no responsibility for the analysis or interpretation of the data as reported here. I would also like to thank the School of Health and Social Development, Deakin University, for providing funding for this work through the Research Small Grants Scheme. Further, I would like to thank Margaret Shield for her assistance with the preparation of the data for this study and Associate Professor Christopher Stevenson for his statistical guidance and support. 


\section{References}

Agerbo, E., Mortensen, P. B. \& Munk-Olsen, T. (2013). 'Childlessness, parental mortality and psychiatric illness: a natural experiment based on in vitro fertility treatment and adoption', Journal of Epidemiology \& Community Health, 67, 374-376.

Albertini, M. \& Mencarini, L. (2011). Childlessness and support neworks in later life - a new public welfare demand? Evidence from Italy. Retrieved from Italy: www.carloalberto.org/working_papers

Albertini, M. \& Mencarini, L. (2014). 'Childlessness and Support Networks in Later Life: New Pressures on Familistic Welfare States?', Journal of Family Issues, 35(3), 331-357.

Australian Bureau of Statistics (ABS). (2008). Australian social trends 2008: how many children have women in Australia had? Cat. No. 4102.0.

Australian Bureau of Statistics (ABS). (2012). 2011 Census Community Profiles: Time Series Profile (Catalogue number 2003.0). Retrieved from: http://www.censusdata.abs.gov.au/census_services/getproduct/census/2011/commu nityprofile/0?opendocument\&navpos $=220$

Australian Demographic \& Social Research Institute. (May 25, 2009). Negotiating the Life Course. Retrieved from http://lifecourse.anu.edu.au/

Bachrach, C. A. (1980). 'Childlessness \& Social Isolation among the Elderly', Journal of Marriage and the Family, 42(3), 627-637.

Baxter, J., Hewitt, B. \& Haynes, M. (2008). 'Life Course Transitions and Housework: Marriage, Parenthood, and Time on Housework', Journal of Marriage \& Family, 70, 259-272.

Berkman, L. F. (1984). 'Assessing the physical health effects of social networks and social support', Annual Review of Public Health, 5, 413-432.

Berkman, L. F. \& Glass, T. (2000). 'Social integration, social networks, social support and health', In L. F. Berkman \& I. Kawachi (Eds.), Social Epidemiology. New York: Oxford University Press.

Bowling, A. (2005). 'Just one question: If one question works, why ask several?', Journal of epidemiology and community health, 59(5), 342-345.

Breusch, T. \& Gray, E. (2005). 'Negotiating the Life Course Survey: Introduction and Perspective', Australian Journal of Labour Economics, 8(2), 111-119.

Cannold, L. (2004). 'Declining marriage rates and gender inequity in social institutions: towards an adequately complex explanation for childlessness', People and Place, 12(4), 1-11.

Cannold, L. (2005). What, no baby? Why women are losing the freedom to mother, and how they can get it back. Freemantle: Curtin University Books.

Chou, K.-L. \& Chi, I. (2004). 'Childlessness and psychological well-being in Chinese older adults', International Journal of Geriatric Psychiatry, 19(5), 449-457.

Connell, R. W. (2002). Gender. Short Introductions. Cambridge: Polity Press.

Commission on Social Determinants of Health (CSDH). (2008). Closing the gap in a generation: health equity through action on the social determinants of health. Final Report of the Commission on Social Determinants of Health. Retrieved from Geneva: http://whqlibdoc.who.int/publications/2008/9789241563703_eng.pdf

Daniluk, J. (2001). 'Reconstructing their lives: a longitudinal, qualitative analysis of the transition to biological childlessness for infertile couples', Journal of Counseling \& Development, 79(4), 439-449.

Dykstra, P. (2006). 'Off the Beaten Track: Childlessness and Social Integration in Late Life', Research on Ageing, 28(6), 749-767.

Dykstra, P. A. \& Hagestad, G. O. (2007). 'Childlessness and Parenthood in Two Centuries: Different Roads--Different Maps?', Journal of Family Issues, 28(11), 1518-1532.

Eckert, P. (1993). 'Cooperative competition in adolsecent "Girl Talk"', In D. Tannen (Ed.), Gender and Conversational Interaction (pp. 32-61). New York Oxford University Press. 
Eng, P., Rimm, E., Fitzmaurice, G. \& Kawachi, I. (2002). 'Social ties and change in social ties in relation to subsequent total and cause-specific mortality and coronary heart disease incidence in men', American Journal of Epidemiology, 155(8), 700-709.

Gillespie, R. (2000). 'When no means no: Disbelief, disregard and deviance as discourses of voluntary childlessness', Women's studies international forum, 23(2), 223-234.

Goldberg, D. P., Gater, R., Sartorius, N., Ustun, T. B., Piccinelli, M., Gureje, O. \& Rutter, C. (1997). 'The validity of two versions of the GHQ in the WHO study of mental illness in general health care', Psychological Medicine, 27(01), 191-197.

Graham, M. (2015). 'Is Being Childless Detrimental to a Woman's Health and Well-Being Across Her Life Course?', Womens Health Issues, 25(2), 176-184.

Graham, M., Hill, E., Shelley, J. \& Taket, A. (2011). 'An examination of the health and wellbeing of childless women: A cross-sectional exploratory study in Victoria, Australia', BMC Women's Health, 11(1).

Graham, M. L., McKenzie, H., Turnbull, B. \& Taket, A. R. (2019). "Them and us": The experience of social exclusion among women without children in their postreproductive years', Journal of Research in Gender Studies, 9(1), 71-104.

Hansen, T., Slagsvold, B. \& Moum, T. (2009). 'Childlessness and Psychological Well-Being in Midlife and Old Age: An Examination of Parental Status Effects Across a Range of Outcomes', Social Indicators Research, 94(2), 343-362.

Holton, S., Fisher, J. \& Rowe, H. (2010). 'Motherhood: is it good for women's mental health?', Journal of Reproductive and Infant Psychology, 28(3), 223-239.

Huijts, T., Kraaykamp, G. \& Subramanian, S. V. (2013). 'Childlessness and Psychological Well-Being in Context: A Multilevel Study on 24 European Countries', European Sociological Review, 29(1), 32-47.

Ishii-Kuntz, M. \& Seccombe, K. (1989). 'The impact of children upon social support networks throughout the life course', Journal of Marriage and the Family, 51(3), 777-790.

Kendig, H., Dykstra, P., Van Gaalen, R. \& Melkas, T. (2007). 'Health of aging parents and childless individuals', Journal of Family Issues, 28(11), 1457-1486.

Klemetti, R., Raitanen, J., Sihvo, S., Saarni, S. \& Koponen, P. (2010). 'Infertility, mental disorders and well-being--a nationwide survey', Acta Obstetricia Et Gynecologica Scandinavica, 89(5), 677-682.

Koropeckyj-Cox, T. (1998). 'Loneliness and depression in middle and old age: Are childless more vulnerable?', Journal of Gerontology, 53B(6), S303-311.

Lang, F. R., Wagner, J., Wrzus, C. \& Neyer, F. J. (2013). 'Personal effort in social relationships across adulthood', Psychology and Aging, 28(2), 529-539.

Lawlor, D., Emberson, J., Ebrahim, S., Whincup, P., Wannamethee, S., Walker, M. \& Smith, G. D. (2003). 'Is the Association Between parity and Coronary Heart Disease Due to Biological Effects of Pregnancy or Adverse Lifestyle Risk Factors Associated with Child-Rearing?: Finding from the British Women's Heart and Health Study and the British Regional Heart Study', Circulation, 107(9), 1261-1264.

Letherby, G. (1999). 'Other than mother and mothers as others: The experience of motherhood and non-motherhood in relation to 'infertility' and 'involuntary childlessness", Women's studies international forum, 22(3), 359-372.

Letherby, G. (2000). 'Images and representations of non-motherhood', Reproductive Health Matters, 8(16), 143.

Letherby, G. (2002). 'Childless and Bereft?: Stereotypes and Realities in Relation to 'Voluntary' and 'Involuntary' Childlessness and Womanhood', Sociological Inquiry, 72(1), 7-20.

Maher, J. M. \& Saugeres, L. (2007). 'To be or not to be a mother?: Women negotiating culutral representations of mothering', Journal of Sociology, 43(1), 5-20.

McDonald, P., Evans, A., Baxter, J. \& Gray, E. (2000). 'The Negotiating the Life Course Survey experience'. Retrieved from:

http://lifecourse.anu.edu.au/publications/Discussion_papers/NLCDP001.pdf

McMunn, A., Bartley, M. \& Kuh, D. (2006). 'Women's health in mid-life: life course social roles and agency as quality', Social Science \& Medicine, 63(6), 1561-1572. 
Miettinen, A., Rotkirch, A., Szalma, I., Donno, A. \& Tanturri, M.-L. (2015). 'Increasing childlessness in Europe: time trends and country differences', Familes and Society Working Paper Series - Changing families and sustainable societies: Policy contexts and diversity over the life course and across generations, 33, 1-66.

Morell, C. (1994). Unwomanly conduct: The challenges of intentional childlessness. Great Britain: Routledge.

Nomaguchi, K. M. \& Milkie, M. A. (2003). 'Costs and Rewards of Children: The Effects of Becoming a Parent on Adults' Lives', Journal of Marriage \& Family, 65(2), 356-374.

Park, K. (2002). 'Stigma management among the voluntary childless', Sociological Perspectives, 45(1), 21-45.

Reidpath, D. D., Chann, K. Y., Gifford, S. M. \& Allotey, P. (2005). 'He hath the French pox: Stigma, social value and social exclusion', Sociology of Health and IIIness, 27(4), 468489.

Reimondos, A. \& Trevenar, S. (2013). Appendix: Negotiating the Life Course Project. In A. Evans \& J. Baxter (Eds.), Negotiating the Life Course. Stability and Change in Life Pathways: Springer.

Rich, S., Taket, A., Graham, M. \& Shelley, J. (2011). 'Unnatural', 'Unwomanly', 'Uncreditable' and 'Undervalued': The significance of being a childless woman in Australian society', Gender Issues, 28(4), 226-247.

Rowland, R. (1982). 'An Exploratoy Study of the Childfree Lifestyle', Australian \& New Zealand Journal of Sociology, 18(1), 17-30.

Rowlands, I. \& Lee, C. (2006). 'Choosing to have children or choosing to be childfree: Australian students' attitudes towards the decisions of heterosexual and lesbian women', Australian Psychologist, 41(1), 55-59.

Tietjens-Meyers, D. (2001). 'The Rush to Motherhood - Pronatalist Discourse and Women's Autonomy', Signs: Journal of Women in Culture \& Society, 26(3), 735-773.

Turnbull, B., Graham, M. \& Taket, A. (2016a). 'The nature and extent of social exclusion of Australian childless women in their reproductive years: an exploratory mixed-methods study', Social Inclusion, 4(1), 102-115.

Turnbull, B., Graham, M. \& Taket, A. (2016b). 'Pronatalism and Social Exclusion in Australian Society: Experiences of Women in their reproductive Years with No Children', Gender Issues, 34, 333-354.

Turnbull, B., Graham, M. \& Taket, A. (2016c). 'Social connection and exclusion of Australian women with no children during midlife', Journal of Social Inclusion, 7(2), 65-85.

Veevers, J. E. (1974). 'Voluntary Childlessness and Social Policy: An Alternative View', The Family Coordinator, 23(4), 397-406.

Vikström, J., Bladh, M., Hammar, M., Marcusson, J., Wressle, E. \& Sydsjö, G. (2011). 'The influences of childlessness on the psychological well-being and social network of the oldest old', BMC Geriatrics, 11, 78-78.

Wagner, J., Wrzus, C., Neyer, F. J. \& Lang, F. R. (2015a). 'Social network characteristics of early midlife volunraliry and involunatarily childless couples', Journal of Family Issues, 36(1), 87-110.

Wagner, J., Wrzus, C., Neyer, F. J. \& Lang, F. R. (2015b). 'Social Network Characteristics of Early Midlife Voluntarily and Involuntarily Childless Couples', Journal of Family Issues, 36(1), 87-110.

Wenger, G. C., Dykstra, P. A., Melkas, T. \& Knipscheer, K. C. P. M. (2007). 'Social embeddedness and late-life parenthood: Community activity, close ties and support networks', Journal of Family Issues, 28(11), 1419-1456.

Wu, Z. \& Hart, R. (2002). 'The mental health of the childless elderly', Sociological Inquiry, 71(1), 21-42. 


\section{Biographical Notes}

Melissa Graham is an Associate Professor in Public Health at La Trobe University. She is the Deputy Director of the Centre for Health through Action on Social Exclusion (CHASE), Deakin University. Associate Professor Graham has a particular interest in women without children, social inclusion and support, and consequent health and wellbeing. 